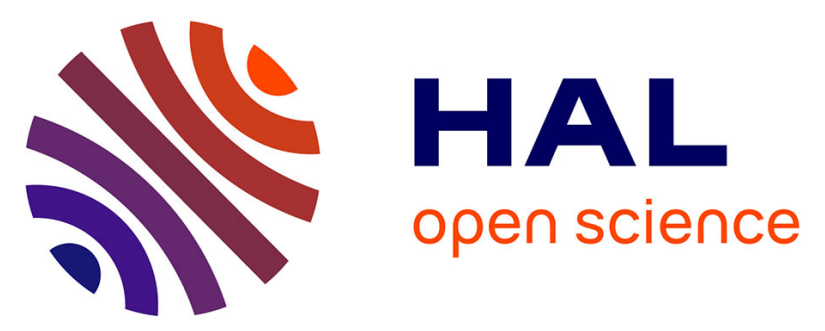

\title{
Vitrification of immature and in vitro matured bovine cumulus-oocyte complexes: effects on oocyte structure and embryo development
}

Dowglish F. Ferreira-Chaves, Emilie Corbin, Carmen Alminana-Brines, Yann Locatelli, Joanna M.G. Souza-Fabjan, Maajid H. Bhat, Vicente J.F. Freitas, Pascal Mermillod

\section{To cite this version:}

Dowglish F. Ferreira-Chaves, Emilie Corbin, Carmen Alminana-Brines, Yann Locatelli, Joanna M.G. Souza-Fabjan, et al.. Vitrification of immature and in vitro matured bovine cumulus-oocyte complexes: effects on oocyte structure and embryo development. Livestock Science, 2017, 199, pp.50-56. 10.1016/j.livsci.2017.02.022 . hal-01603850

\section{HAL Id: hal-01603850 https://hal.science/hal-01603850}

Submitted on 25 May 2020

HAL is a multi-disciplinary open access archive for the deposit and dissemination of scientific research documents, whether they are published or not. The documents may come from teaching and research institutions in France or abroad, or from public or private research centers.
L'archive ouverte pluridisciplinaire HAL, est destinée au dépôt et à la diffusion de documents scientifiques de niveau recherche, publiés ou non, émanant des établissements d'enseignement et de recherche français ou étrangers, des laboratoires publics ou privés.

$$
\text { Copyright }
$$




\section{Author's Accepted Manuscript}

Vitrification of immature and in vitro matured bovine cumulus-oocyte complexes: effects on oocyte structure and embryo development

Dowglish F. Chaves, Emilie Corbin, Carmen Almiñana, Yann Locatelli, Joanna M.G. SouzaFabjan, Maajid H. Bhat, Vicente J.F. Freitas, Pascal Mermillod

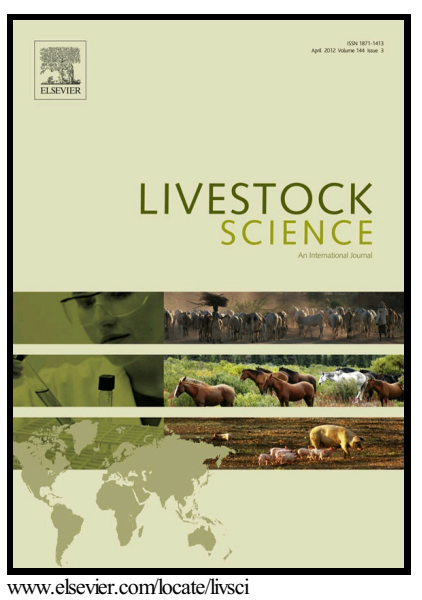

PII: $\quad$ S1871-1413(17)30060-4

DOI: $\quad$ http://dx.doi.org/10.1016/j.livsci.2017.02.022

Reference: LIVSCI3161

To appear in: Livestock Science

Received date: 7 July 2016

Revised date: 14 February 2017

Accepted date: 20 February 2017

Cite this article as: Dowglish F. Chaves, Emilie Corbin, Carmen Almiñana, Yanr Locatelli, Joanna M.G. Souza-Fabjan, Maajid H. Bhat, Vicente J.F. Freitas anc Pascal Mermillod, Vitrification of immature and in vitro matured bovin cumulus-oocyte complexes: effects on oocyte structure and embryo developmen 1 Livestock Science, http://dx.doi.org/10.1016/j.livsci.2017.02.022

This is a PDF file of an unedited manuscript that has been accepted fo publication. As a service to our customers we are providing this early version o the manuscript. The manuscript will undergo copyediting, typesetting, an review of the resulting galley proof before it is published in its final citable form Please note that during the production process errors may be discovered whic could affect the content, and all legal disclaimers that apply to the journal pertain 
Vitrification of immature and in vitro matured bovine cumulus-oocyte complexes: effects on oocyte structure and embryo development

Dowglish F. Chaves ${ }^{\mathrm{a}, \mathrm{b}}$, Emilie Corbin ${ }^{\mathrm{b}}$, Carmen Almiñana ${ }^{\mathrm{b}}$, Yann Locatelli ${ }^{\mathrm{b}, \mathrm{c}}$, Joanna M. G. Souza-Fabjan $^{\mathrm{d}}$, Maajid H. Bhat ${ }^{\mathrm{a}}$, Vicente J. F. Freitas ${ }^{\mathrm{a}}$, Pascal Mermillod ${ }^{\mathrm{b} *}$

${ }^{a}$ Laboratório de Fisiologia e Controle da Reprodução, Universidade Estadual do Ceará, Fortaleza-CE, Brazil

${ }^{\mathrm{b}}$ INRA, UMR7247 Physiologie de la Reproduction et des Comportements, INRA, Nouzilly, France

${ }^{\mathrm{c}}$ Réserve de la Haute Touche, Museum National d'Histoire Naturelle, Obterre, France ${ }^{\mathrm{d}}$ Departamento de Patologia e Clínica Veterinária, Faculdade de Veterinária, Universidade Federal Fluminense, Niterói-RJ, Brazil

*Correspondence to: Pascal Mermillod UMR7247 Physiologie de la Reproduction et des Comportements, INRA, Nouzilly, France Tel:/Fax: +33 608279759.

pascal.mermillod@tours.inra.fr

\begin{abstract}
This study aimed to verify the effects of cryoprotectant and Open Pulled Straw (OPS) vitrification on ultrastructural changes in bovine oocytes. In experiment 1 , the cryoprotectant exposure was analyzed by distributing immature and matured cumulus-oocyte complexes (COCs) in groups: control immature, immature and exposed to one vitrification solution (IVS1), immatured and exposed to two vitrification solutions (IVS1-2), matured and exposed to one vitrification solution (MVS1), matured and exposed to two vitrification solutions (MVS1-2), control matured, IVS1 post in vitro maturation (IVS1 post IVM) and IVS1-2 post
\end{abstract}


in vitro maturation (IVS1-2 post IVM). In experiment 2, immature and matured COCs were distributed in: control and vitrified by OPS using VS1-2. Sample COCs from both experiments were evaluated for mitochondrial distribution, nuclear lamins (immature COCs) and meiotic spindle (matured COCs). In both experiments, COCs were in vitro matured and fertilized. In experiment I, nuclear lamins in immature COCs exhibited higher proportion of structures with irregular shape when treated with VS1 and VS1-2. Immature and matured COCs treated with VS1-2, and matured COCs treated with VS1 had lower $(\mathrm{P}<0.05)$ blastocyst development $(29 \%, 20 \%$ and $8 \%$, respectively) than control and immature COCs treated with VS1 (51\% and $41 \%$, respectively). In experiment 2 , immature oocytes exhibited more $(\mathrm{P}<0.05)$ structures with irregular lamin (72\%) than control (9\%). Vitrification of matured COCs did not induce abnormalities of meiotic spindle, compared to control matured ( $25 \%$ and $37 \%$, respectively) $(\mathrm{P}>0.05)$. The cleavage rate was higher $(\mathrm{P}<0.05)$ in matured vitrified than immature vitrified group (19\% vs. $8 \%$ ). In conclusion, immature COCs were more tolerant to cryoprotectant exposure. However, matured oocytes showed better embryo development (cleavage) after vitrification.

Keywords: Meiotic spindle; Nuclear lamin; Mitochondrial distribution; Blastocyst; Cryoprotectant exposure.

\section{Introduction}

Cryopreservation is an important tool for assisted reproductive biotechnologies. Achievement of higher efficiency of oocyte cryopreservation has remained a challenge for years. The ability 
to effectively cryopreserve oocytes has a great potential for basic research, commercial applications and would significantly improve animal breeding programs and biodiversity preservation. Indeed, cryopreservation of sperm, oocytes and embryos provides safeguard against loss through diseases, genetic drift and catastrophic loss of rare or endangered animal genetic resources (Zhou and Li, 2013). However, the cryopreservation of bovine oocytes remains inefficient, as oocytes have been shown to be highly sensitive to both chilling and exposure to cryoprotectants agents (Diez et al., 2012).

After cryopreservation, oocytes display compromised developmental competence that may be due to damages to the meiotic apparatus, including spindle disorganization and loss of microtubules as well as other ultrastructural alterations (Albarracin et al., 2005; Morató et al., 2008a). Moreover, to understand the mechanisms underlying their development impairment, it is important to investigate mitochondrial modifications in cryopreserved oocytes. Previous studies have demonstrated that changes in mitochondria may contribute to the reduced viability of cryopreserved oocytes (Rho et al., 2002; Chang-Liang et al., 2010). Rho et al. (2002) demonstrated that following vitrification, bovine oocytes at the germinal vesicle (GV) stage have shown multiple ruptured mitochondria in highly vacuolated cytoplasm, whereas mature oocytes display abnormal mitochondrial distribution.

The oocytes are enclosed in follicles and remain in GV (immature) until the meiosis resumption with chromosome condensation and rupture of the nuclear envelope, known as germinal vesicle breakdown (GVBD). Meiosis continues until metaphase-II (matured), without reformation of the nuclear envelope (Arnault et al., 2010). The nuclear lamins are located between the inner this envelope and the peripheral chromatin providing the nucleus with mechanical stability and nuclear shape. In addition to their structural functions, lamins 
are involved in several nuclear processes such as DNA replication, transcription, DNA repair and the epigenetic organization of chromatin.

Studies have indicated that alterations in their structure can disrupt these activities and cause genetic diseases (Dechat et al., 2008; 2009). However, despite their physiological importance, there are no studies about possible alterations induced by cryoprotectant exposure and vitrification.

Although, the effect of vitrification process or cryoprotectant exposure have been studied in bovine oocyte (Morató et al., 2008b; Prentice et al., 2011; Sripunya et al., 2014), studies about their effect on ultrastructure are scarce. Vitrification uses a high concentration of cryoprotectants, potentially damaging the ultrastructure. Therefore, to investigate the reduced developmental competence of immature and in vitro matured oocytes following vitrification, it is important to understand the individual components of the vitrification system (PrenticeBiensch et al., 2012). Hence, the current study investigated the influence of cryoprotectant exposure in low and high concentration and Open Pulled Straw (OPS) vitrification of immature and in vitro matured cumulus-oocytes complexes (COCs) on oocyte structure (mitochondria, meiotic spindle and nuclear lamin) and further embryo development.

\section{Material and methods}

Except otherwise indicated, chemicals were purchased from Sigma Chemical Co. (Saint Louis, MO, USA) and plastics from Nunc (Nalgen Nunc International, Roskilde, Denmark).

\subsection{Oocyte collection and in vitro maturation (IVM)}


Ovaries obtained from the local slaughterhouse were transported to the laboratory in a thermos box containing saline solution $(\mathrm{NaCl} 0.9 \% \mathrm{w} / \mathrm{v})$ at $34^{\circ} \mathrm{C}$. Ovaries were washed in pre-warmed fresh saline and oocytes were aspirated from all visible follicles between 2 and $8 \mathrm{~mm}$ in diameter with an 18-gauge short beveled needle connected to a tube under controlled vacuum (30 mm Hg). COCs were selected under a stereomicroscope (Nikon Corporation, Tokyo, Japan) and only oocytes enclosed in a compact cumulus with an evenly granulated cytoplasm were selected for experiments. COCs were rinsed in medium consisting of HEPES-buffered TCM199, $0.4 \mathrm{~g} / \mathrm{l}$ bovine serum albumin (BSA) and $4 \mu \mathrm{g} / \mathrm{ml}$ gentamicin. For IVM, COCs were washed twice and distributed into groups of 45-50 in four-well dishes containing $500 \mu$ l of maturation medium which consisted in TCM199 supplemented with 10 ng/ml Epidermal Growth Factor (EGF), 5 IU/ml human Chorionic Gonadotrophin (hCG), 10 IU/ml equine Chorionic Gonadotrophin (eCG), 19 ng/ml Insulin-like Growth Factor-1 (IGF-1), 2.2 ng/ml Fibroblast Growth Factor, $5 \mu \mathrm{g} / \mathrm{ml}$ insulin, $5 \mu \mathrm{g} / \mathrm{ml}$ transferine, $5 \mathrm{ng} / \mathrm{ml}$ selenium, $90 \mu \mathrm{g} / \mathrm{ml} \mathrm{L-}$ cysteine, $0.1 \mathrm{mM} \beta$-mercaptoethanol, $75 \mu \mathrm{g} / \mathrm{ml}$ vitamin $\mathrm{C}, 720 \mu \mathrm{g} / \mathrm{ml}$ glycine, $0.1 \mathrm{mg} / \mathrm{ml}$ glutamine and $110 \mu \mathrm{g} / \mathrm{ml}$ pyruvate. COCs were incubated for $22 \mathrm{~h}$ at $38.8^{\circ} \mathrm{C}$ in a humidified atmosphere of $5 \% \mathrm{CO}_{2}$ in air.

\subsection{Cryoprotectant exposure and vitrification procedure}

All procedures were carried out at room temperature $\left(20-25^{\circ} \mathrm{C}\right)$. The base medium for preparation of all cryoprotectant solutions was holding medium (HM), which consisted in HEPES-buffered TCM199 supplemented with 20\% (v/v) newborn calf serum. Cryoprotectant exposure was perfomed with treatements with vitrification solution 1 - VS1 (7.5\% dimethyl sulfoxide-DMSO + 7.5\% ethylene glycol-EG in HM) or VS1 and vitrification solution 2 VS2 (16\% DMSO, 16\% EG + $1 \mathrm{M}$ of sucrose in HM) - VS1-2 (Table 1). COCs of all groups 
were washed in HM for 3 min and processed in VS1 for 15 min approximately. Then, only COCs exposed to VS1-2 were transferred into two successive drops of VS2 for 20 seconds each, and exposed to warming solution 1 (WS1), which consisted in HM plus 1 M sucrose prewarmed at $37{ }^{\circ} \mathrm{C}$, and incubated for $1 \mathrm{~min}$ in this solution. Thereafter, all treated groups were exposed to warming solution 2 (WS2), HM containing $0.5 \mathrm{M}$ sucrose, incubated for 3 min, and washed twice in $\mathrm{HM}$ for $5 \mathrm{~min}$.

Vitrification was performed by the use of the OPS method as previously described by Vajta et al. (1998) with few modifications. Immature and matured COCs were vitrified by OPS using the same procedure as decribed for VS1-2 treatment. COCs were loaded in OPS (Minitub, Tiefenbach, Germany) after VS2 exposure and plunged into liquid nitrogen. Finally, for warming, the tip of the straw was plunged in WS1. Thereafter, the COCs were transferred into WS2 and washed twice in HM.

\subsection{In vitro fertilization (IVF)}

Control, exposed and vitrified COCs were fertilized using the same conditions (Cordova et al., 2014). All the samples were washed two times in fertilization medium, and then transferred in groups of 50 into four-well dishes containing $250 \mu 1$ of fertilization medium, which was composed of Tyrode's medium with $25 \mathrm{mM}$ bicarbonate, $10 \mathrm{mM}$ lactate, $1 \mathrm{mM}$ pyruvate, $6 \mathrm{mg} / \mathrm{ml}$ fatty acid free BSA and $10 \mu \mathrm{g} / \mathrm{ml}$ heparin (Merck Millipore, Darmstadt, Germany). Two straws of semen from the same ejaculate were used per replicate throughout experiments. Motile spermatozoa were obtained by centrifugation of frozen-warmed semen on a discontinuous Percoll (Pharmacia, Uppsala, Sweden) density gradient (45\%/90\%) at $700 \mathrm{~g}$ for 20 min at room temperature. Viable spermatozoa were collected at the bottom of the $90 \%$ fraction and washed in Tyrode medium supplemented with $25 \mathrm{mM}$ bicarbonate, $10 \mathrm{mM}$ 
lactate, $6 \mathrm{mg} / \mathrm{ml} \mathrm{BSA}$ and pelleted by centrifugation at $100 \mathrm{~g}$ for $10 \mathrm{~min}$. Viable sperm were diluted in the appropriate volume of fertilization medium to achieve a final concentration of 2 $\mathrm{x} 10^{6} \mathrm{sperm} / \mathrm{ml}$. A $250 \mu \mathrm{l}$ aliquot of this suspension was added to each well containing oocytes for a final concentration of sperm cells of $1 \times 10^{6} \mathrm{sperm} / \mathrm{ml}$. Spermatozoa and oocytes were coincubated for $18 \mathrm{~h}$ at $38.8^{\circ} \mathrm{C}$ in a humidified atmosphere of $5 \% \mathrm{CO}_{2}$ in air.

\subsection{In vitro culture (IVC)}

Presumptive zygotes were vortexed and washed three times in HEPES-buffered TCM199 containing $0.4 \mathrm{~g} / \mathrm{l} \mathrm{BSA}$ and $4 \mu \mathrm{g} / \mathrm{ml}$ gentamicin, to remove cumulus cells and attached spermatozoa. Zygotes were washed two times in SOF medium (Minitub, Tiefenbach, Germany) supplemented with BME amino acids (50x), MEM amino acids (100x), $3 \mathrm{mM}$ pyruvate, $6 \mathrm{mg} / \mathrm{ml}$ fatty acid free BSA and 5\% FBS and transferred by groups of 25 into fourwell petri dishes containing $25 \mu 1$ drops of culture medium covered with $700 \mu 1$ of mineral oil. The presumptive zygotes were cultured for 8 days at $38.8^{\circ} \mathrm{C}$ in a humidified atmosphere of $5 \%$ $\mathrm{O}_{2}, 5 \% \mathrm{CO}_{2}$, and $90 \% \mathrm{~N}_{2}$. Embryo development was recorded on day 2, 6, 7 and 8 post-IVF.

\subsection{Evaluation of mitochondrial distribution}

For mitochondrial staining, COCs were kept in HM after cryoprotectant exposure or warming to approximately $30 \mathrm{~min}$, denuded of cumulus cells by pipetting and cultured in TCM199 without HEPES containing $2 \mu \mathrm{mol} / \mathrm{l}$ Mito Tracker Deep Red FM (Molecular Probes, Eugene, OR, USA) for $45 \mathrm{~min}$ at $38.8^{\circ} \mathrm{C}$ in a humidified atmosphere of $5 \% \mathrm{CO}_{2}$. After washing in HEPES-buffered TCM199 supplemented with BSA (0.4 g/l) and gentamicin $(2.5 \mathrm{ml} / \mathrm{l})$, oocytes were kept in four-well plate and analyzed by confocal microscopy (LSM 780, Zeiss, Göttingen, Germany). After morphological analyzes, some oocytes were considered 
degenerated, these cell showed abnormal appearance, ruptured membrane and vacuolation. The viable oocytes were classified into two categories: mitochondrial distribution throughout the whole cytoplasm (central) or in the peripheral region (peripheral). The survival rate was calculated as the number of viable oocytes divided by the total number of oocytes evaluated.

\subsection{Nuclear lamin and meiotic spindle}

For immunostaining, COCs were kept in HM after cryoprotectant exposure or warming to approximately $1 \mathrm{~h}$ and thereafter, denuded, fixed and permeabilized in $4 \%(\mathrm{w} / \mathrm{v})$

paraformaldehyde, $0.5 \%(\mathrm{v} / \mathrm{v})$ Triton X-100 in phosphate-buffered saline (PBS) supplemented with $0.5 \%$ of BSA for $20 \mathrm{~min}$ at room temperature. Samples were washed three times in PBSBSA, and transferred into blocking solution (PBS-BSA supplemented with 5\% of goat pre immune inactivated serum) and kept in this solution for $2 \mathrm{~h}$ at room temperature. Coincubation with primary antibodies in PBS supplemented with $0.5 \%$ of BSA, monoclonal anti $\alpha$-tubulin (1:1000) (T9026, Thermo Fisher Scientific, Waltham, MA, USA) only for matured oocytes and anti lamin A/C (1:100) (MA3-1000, Thermo Fisher Scientific) only for immature oocytes were carried out for $1 \mathrm{~h}$ at $37^{\circ} \mathrm{C}$, and $2 \mathrm{~h}$ at room temperature, respectively. Immature and matured oocytes were washed three times in PBS-BSA for 10 min and incubated with secondary antibody, Daylight 594 (1:500) (35510, Thermo Fisher Scientific) in PBS supplemented with $0.5 \%$ of BSA for $2 \mathrm{~h}$ in a dark at $37^{\circ} \mathrm{C}$. Oocytes were then incubated in Hoechst 33342 (1/100) for 5 min in dark at room temperature and mounted on microscope slide and covered with a coverslip. The slides were stored at $4^{\circ} \mathrm{C}$ and protected from light until observation. A laser-scanning confocal microscope (LSM 700, Zeiss, Göttingen, Germany) was used to examine tubulin, nuclear lamin (A594; excitation $488 \mathrm{~nm}$ ) and chromatin (DAPI; excitation $405 \mathrm{~nm}$ ). Nuclear lamin organization was classified according to Arnault et al. 
(2010): lamin that showed staining as a regular circle following the nuclear envelope was classified as regular, whereas, nuclear lamin that showed modifications in the shape, exhibiting irregular circle with local thickening, was classified as irregular. Also, spindle morphology and chromosomes were classified into two categories, as previously described by Caamaño et al. (2013): normal (barrel-shaped with chromosomes clustered as a discrete bundle at the metaphase plate and microtubules crossing the length of the spindle from pole to pole) or abnormal (microtubules not organized as typical spindles or some microtubules disassembled with chromosomes showing some degree of disarrangement or displacement from the metaphase plate).

\subsection{Experimental design}

a. Effect of cryoprotectant exposure on mitochondrial distribution, meiotic spindle, lamin and embryo development in immature and in vitro matured COCs

The experiment I was performed in four replicates. Initially, immature and matured COCs were distributed in five groups: control (immature COCs without exposure), treated with VS1 and WS2 (immature - IVS1 and matured - MVS1) or treated VS1, VS2, WS1 and WS2 (immature - IVS1-2 and matured - MVS1-2) (Table 1). Samples of these groups were processed $1 \mathrm{~h}$ after cryoprotectant exposure to analyze lamin structure (immature, $\mathrm{n}=64$ ), meiotic spindle (matured, $\mathrm{n}=49$ ) and mitochondrial distribution (for both groups, $\mathrm{n}=89$ ). Futhermore, to visualize cryoprotectant exposure effects on maturation of immature COCs, samples from control, IVS1 and IVS1-2 after IVM were taken to form three new groups (control matured, IVS1 post IVM and IVS1-2 post IVM, respectively) only to analyze mitochondrial distribution $(\mathrm{n}=58)$ and meiotic spindle $(\mathrm{n}=65)$. For evaluate the embryo 
development,739 COCs from five initial groups were subjected, approximately $1 \mathrm{~h}$ after exposure, to IVM (immature ones), IVF and IVC.

b. Effect of vitrification by OPS on mitochondrial distribution, meiotic spindle, lamin and embryo development in immature and in vitro matured COCs

The experiment II was performed in four replicates. Initially, immature and matured COCs were distributed in three groups: control (immature COCs without vitrification), immature vitrified (IV) and matured vitrified (MV) (Table 1). Samples of these groups were processed 1 $\mathrm{h}$ after warming to analyze lamin structure (immature, $\mathrm{n}=51$ ), meiotic spindle (matured, $\mathrm{n}=39$ ) and mitochondrial distribution (for both groups, $n=58$ ). Futhermore, to visualize vitrification effects on maturation, samples from control and IV after IVM were taken to form two new groups (control matured and IV post IVM, respectively) only to analyze mitochondrial distribution $(n=44)$ and meiotic spindle $(n=26)$. For evaluate the embryo development, 525 COCs from three initial groups were subjected, approximately $1 \mathrm{~h}$ after warming, to IVM (immature ones), IVF and IVC.

\subsection{Statistical Analysis}

Data were statistically analyzed using the GraphPad Prism 5.0a software. The chi-square test was used to compare data among the experimental groups. The level of statistical significance was set at $\mathrm{P}<0.05$.

\section{Results}

\subsection{Experiment I}

\subsubsection{Mitochondrial distribution}


Figure 1 shows representative images of the observation of mitochondrial distribution. The frequencies of oocytes with peripheral or central mitochondrial distributions in the different groups are shown in Table 2. The maturation induced a significant migration of mitochondria from peripheral to central location in the oocytes of control group $(\mathrm{P}<0.05)$. A similar central location was observed in oocytes exposed to cryoprotectants at the matured stage.

Mitochondria migration was also observed after IVM of immature oocytes exposed to IVS1-2 post IVM.

\subsubsection{Meiotic spindle and nuclear lamins}

Figure 2 shows representative images of regular and irregular structures of lamins, and normal and abnormal spindle organization. The cryoprotectant exposure significantly affected the spindle integrity in the MVS1-2 group, when compared to control group, with $61 \%(17 / 28)$ of abnormal meiotic spindle ( $\mathrm{P}<0.05)$. While in the control matured, MVS1, IVS1 post IVM and IVS1-2 post IVM groups, spindle abnormalities were observed as 6\% (1/18), 19\% (4/21), $22 \%(5 / 23)$ and $21 \%(5 / 24)$, respectively $(\mathrm{P}>0.05)$. Concerning the organization of nuclear lamin in immature COCs exposed to cryoprotectants, it was found that the IVS1 and IVS1-2 groups exhibited a higher proportion $(\mathrm{P}<0.05)$ of structures with irregular shape $(32 \%, 6 / 17$ and $35 \%, 8 / 25$, respectively) compared to control group $(0 \%, 0 / 22)$.

\subsubsection{Embryo development}

The effects of cryoprotectant exposure on the COCs developmental competence is shown in Table 3. Cleavage, blastocyst and hatching rates were significantly affected by the experimental procedure. All the treated groups showed a lower $(\mathrm{P}<0.05)$ cleavage rate than the control group. In addition, IVS1-2, MVS1 and MVS1-2 groups exhibited lower $(\mathrm{P}<0.05)$ 
blastocyst rates at day 8 post insemination (29\%, $20 \%$ and $8 \%$, respectively) compared to the control (51\%) and IVS1 (41\%) groups. Higher hatching rates were observed in control (22\%) and IVS1 (16\%) groups as compared to the IVS1-2 (6\%), MVS1 (7\%) and MVS1-2 (1\%) groups $(\mathrm{P}<0.05)$.

\subsection{Experiment II}

\subsubsection{Mitochondrial distribution}

In the control matured group, migration of mitochondria was observed toward a central, whereas in immature control, mitochondrial location was peripheral (Table 4). Although, there were no statistical differences $(\mathrm{P}>0.05)$ between vitrified/warmed oocytes (either in IV or MV) and non-vitrified control oocytes in terms of mitochondrial distribution, there was statistical difference $(\mathrm{P}<0.05)$ between control and matured control COCs.

\subsubsection{Meiotic spindle and nuclear lamins}

Nuclear lamins organization was significantly affected by vitrification. Immature oocytes exhibited higher $(\mathrm{P}<0.05)$ proportion of structures with irregular shape $(72 \%, 21 / 29)$ compared to control group $(9 \%, 2 / 22)$. The meiotic spindle was not affected by vitrification, there were no differences between control matured (25\%, 5/20) and MV (37\%, 7/19) groups. In contrast, it was not possible to observe the meiotic spindle and polar body extrusion in analyzed oocytes (0/26) from IV post IVM group.

\subsubsection{Embryo development}

The effects of the vitrification by OPS on the developmental competence in immature and matured COCs are described in Table 5. In this experiment, the control group showed higher 
cleavage, blastocyst and hatching rates compared to IV and MV COCs $(\mathrm{P}<0.05)$. The proportion of cleavage in the MV group $(19 \%)$ was higher $(\mathrm{P}<0.05)$ than in the IV group $(8 \%)$.

\section{Discussion}

In the present study, firstly we compared the outcomes of cryoprotectant exposure on bovine COCs. Osmotic stress resulting from exposure to high concentrations of cryoprotectant could lead oocytes to undergo dramatic volume changes during equilibration (Prentice-Biensch et al., 2012). In this regard, one of the most important factor affecting cell survival during dilution of cryoprotectants is excessive cell swelling (Prentice-Biensch et al., 2012). The toxicity of the cryoprotectant is another problem that could be avoided with an optimum exposure time (Kim et al., 2007). Prentice et al. (2011) demonstrated that 10 min exposure time in concentrations of EG and DMSO (7.5\% each) in equilibration solution was long enough to cause chemical toxicity to bovine COCs. Casillas et al. (2015) and Nohalez et al. (2015) found that equilibration time around $3 \mathrm{~min}$ and similar concentration of cryoprotectants caused a low impact on development in porcine embryo. In our study, COCs were exposed to 15 min in similar solution (VS1) and the results showed decrease of the blastocyst rates in treated groups, except IVS1. Due to the higher cleavage and embryo development rates in VS1 and VS1-2 observed for immature COCs, we suggest that immature oocytes tolerate cryoprotectant exposure better than in vitro matured groups. However, after vitrification, matured COCs showed higher cleavage rates than immature COCs, but there was no significant increase in the blastocyst rates. Studies have demonstrated that in vitro matured oocytes are more resistant to cryopreservation due to their membrane stability during chilling

(Rojas et al., 2004). Furthermore, the influence of cumulus cells is important for the 
developmental competence of oocytes. Carmen et al. (2005) demonstrated that vitrification of immature oocytes caused lysis in the cumulus cells and significantly disrupted communication between oocyte and the cumulus cells. However, when the oocytes were vitrified at the matured stage, cumulus cells did not show any alterations and looked similar to fresh oocytes. We suggest that probably the negative effects of cold stress on cumulus cells may have disturbed the IVM process, interfering on futher embryo development.

Our results demonstrate that after warming, amongst the cleaved embryos, matured oocytes were able to produce blastocysts (3\%), but it was much lower than control oocytes and not significantly different observed in immature COCs. Similar results were obtained by different studies showing slightly lower or similar blastocyst rates of 0\% (Morató et al., 2008c), 1.6\% (Diez et al., 2005) and 2.3\% (Morató et al., 2008d) of bovine matured oocytes vitrified by OPS.

It is well established that during natural cytoplasmic maturation of oocytes, the LH surge results in re-distribution of some organelles in the ooplasm, including mitochondria (Dadarwal et al., 2015). The accumulation of mitochondria in the ooplasm periphery before maturation and central re-location after maturation were described in bovine and porcine oocytes (Sun et al., 2001; Ferreira et al., 2009; Romek et al., 2011). In our experiments, usual mitochondrial distribution of oocytes was not altered by cryoprotectant exposure. The exposure of immature oocytes to cryoprotectants (IVS1-2) did not affect mitochondrial location at the immature stage, nor their translocation to the central region during IVM (IVS1-2 post IVM). Results obtained by Rho et al. (2002) and Chang-Liang et al. (2010) demonstrated that exposure of oocytes to cryoprotectant did not alter mitochondrial appearance. However, the same study revealed that mitochondrial localization in vitrified oocytes was seriously disturbed. Our results indicate abnormal mitochondrial localization in both vitrified groups, and this may be a 
result of oocyte microtubule damage induced by vitrification itself and not by cryoprotectant exposure. In addition, mitochondrial localization is not restored during IVM of immature vitrified oocytes, indicating that the cytoskeleton machinery is altered by vitrification. Under normal conditions, mitochondria migrate from the periphery to the center during oocyte maturation and appear homogeneously distributed throughout the cytoplasm prior to fertilization (Yan et al., 2010).

Both cryoprotectants used in this study, EG and DMSO, are common in many vitrification protocols, but they are considered as toxic due to their cell permeating nature and the high concentrations needed to induce vitrification (Ledda et al., 2007). Moreover, many cryoprotectants are known to induce changes in microtubule organization (Saunders and Parks, 1999). Meiotic spindle assembly and chromosome alignment are basic requirement for normal fertilization and subsequent embryonic development. During meiosis, the meiotic spindle plays an essential role in normal chromosome segregation (Caamaño et al., 2013). Previous studies have shown that the high concentration of cryoprotectants required to achieve vitreous state may exert a highly detrimental effect on spindle configuration (Jiménez-Trigos et al., 2012). Our results indicated that cryoprotectant exposure affected the organization of the meiotic spindle of matured oocytes. This fact may probably explain the decrease in developmental capacity, translating into decreased cleavage and blastocyst rates.

On the other hand, the meiotic spindle was not affected after vitrification of matured COCs, as compared to the control group, while cleavage and blastocyst rates were strongly reduced. The OPS method besides being simple and inexpensive, achieves a vastly increased cooling speed by reducing the volume to be vitrified and narrowing the insulating layer between the cooling agent and the vitrification solution (Vajta et al., 1998). However, abnormalities in meiotic spindle after the vitrification by OPS of in vitro matured bovine oocytes have impaired 
the capacity for further embryo development (Morató et al., 2008a). Morató et al. (2008c) have demonstrated that vitrification of bovine oocytes by OPS led to significantly lower blastocyst rates $(2.3 \%)$, associated with disorganized or decondensed microtubules or chromosomes of matured oocytes.

Vitrification of bovine immature oocytes causes a decline in cAMP levels inside oocytes and low maturation promoting factor (MPF) activity delaying the maturation time of oocytes subjected to IVM (Ezoe et al., 2015). These authors suggested that the maintenance of the intraoocyte cAMP level during IVM improves the poor developmental competence caused by vitrification of oocytes at the GV stage. In our study, IV post IVM group, after confocal analysis, did not show classic signs of maturation, as meiotic spindle and polar body. The delayed maturation of oocytes after vitrification/warming and their poor subsequent development during IVF culture may be the reason for lower rates of cleavage and failure of blastocyst formation in immature COCs.

Kim et al. (2007) also suggested that vitrification is associated with destruction of connections between oocyte and cumulus cells. Studies have shown that the relationship between oocyte and cumulus cells play an important role in metabolic cooperation during the growth phase and final maturation of oocytes via gap junctions (Rojas et al., 2004). Therefore, the low rate of oocytes reaching MII phase after maturation could be due to the damage to gap junctions between cumulus cells and oocytes.

Nuclear lamins are required for proper cell cycle regulation, chromatin organization, DNA replication, cell differentiation and apoptosis (Dechat et al., 2008; 2009). Lamin C is a spliced variant of the LMNA gene product, lamin A. These two lamins differ only in their carboxyterminal region and are generally studied together, as lamin A/C. These nuclear lamins play a key role in nuclear envelope integrity and are present in oocytes at the germinal vesicle stage, 
disappearing during oocyte maturation (Lee et al., 2007; Arnault et al., 2010). This study was the first one to analyze the possible effects of vitrification of immature bovine oocytes on nuclear lamin A/C. Arnault et al. (2010) showed that in vitro oocyte maturation model, lamin $\mathrm{A} / \mathrm{C}$ was progressively dismantled in oocytes resuming meiosis. They hypothesized that some of the oocytes resuming IVM followed to apoptotic pathway. In our study, immature oocytes after warming showed irregular shape in $72 \%$ of oocytes. In apoptotic somatic cells is established the relationship between lamin A and caspase-6 (Ruchaud et al., 2002). Hence, we suggested that apoptotic mechanisms have been activated after vitrification and impaired the further embryo development.

\section{Conclusions}

Immature COCs were more tolerant to the cryoprotectant exposure than the in vitro matured oocytes. However, this cryoprotection was not efficient to protect the nuclear lamin structure and proper mitochondrial distribuition during maturation after warming. Although, in vitro matured COCs showed better embryo development (cleavage) after vitrification, this effect was not maintained up to the end of culture (day 8). Finally, the vitrification of in vitro matured oocytes appeared more promising, but further research should be dedicated to develop new cryoprotective strategies, allowing a better protection of their meiotic spindle.

\section{Conflict of interest}

All authors declare that they do not have any actual or potential conflict of interest including any financial, personal or other relationships with other people or organizations. 


\section{Acknowledgements}

The authors are grateful to CAPES (Brasília, Brazil) for funding (CAPES-COFECUB grant \# 728/11) and fellowships for D.F. Chaves and J.M.G. Souza-Fabjan. V.J.F. Freitas and M.H. Bhat are investigators from CNPq (Brasília, Brazil).

\section{References}

Albarracin, J.L., Morató, R., Rojas, C., Mogas, T., 2005. Effects of vitrification in open pulled straws on the cytology of in vitro matured prepubertal and adult bovine oocytes. Theriogenology 63, 890-901.

Arnault, E., Doussau, M., Pesty, A., Lefèvre, B., Courtot, A.M., 2010. Review: Lamin A/C, caspase-6, and chromatin configuration during meiosis resumption in the mouse oocyte. Reprod. Sci. 17, 102-115.

Caamaño, J.N., Díez, C., Trigal, B., Muñoz, M., Morató, R., Martín, D., Carrocera, S., Mogas, T., Gomez, E., 2013. Assessment of meiotic spindle configuration and post-warming bovine oocyte viability using polarized light microscopy. Reprod. Domest. Anim. 48, $470-476$.

Carmen, D., Paloma, D., Enrique, G., Carlos, O.H., Carolina, T.,Aida, R., Lina, F., Santiago de la,V.,Alba, F., Nieves, F., Maite, C., 2005. Bovine oocyte vitrification before or after meiotic arrest: effects on ultrastructure and developmental ability. Theriogenology 64, 317-333.

Casillas, F., Ducolomb, Y., Lemus, A.E., Cuello, C., Betancourt, M., 2015. Porcine embryo production following in vitro fertilization and intracytoplasmic sperm injection from 
vitrified immature oocytes matured with a granulosa cell co-culture system. Cryobiology 71, 299-305.

Chang-Liang, Y., Xiang-Wei, F., Guang-Bin, Z., Xue-Ming, Z., Lun, S., Shi-En, Z., 2010. Mitochondrial behaviors in the vitrified mouse oocyte and its parthenogenetic embryo: effect of Taxol pretreatment and relationship to competence. Fertil. Steril. 93, 959-966.

Cordova, A., Uzbekova, S., Ponsart, C., Locatelli, Y., Mermillod, P., 2014. Development rate and gene expression of IVP bovine embryos cocultured with bovine oviduct epithelial cells at early or late stage of preimplantation development. Theriogenology $81,1163-$ 1173.

Dadarwal, D., Adams, G.P., Hyttel, P., Brogliatti, G.M., Caldwell, S., Singh, J., 2015 Organelle reorganization in bovine oocytes during dominant follicle growth and regression . Reprod. Biol. Endocrinol. 13, 124.

Dechat, T., Pfleghaar, K., Sengupta, K., Shimi, T., Shumaker, D.K., Solimando, L., Goldman, R.D., 2008. Nuclear lamins: major factors in the structural organization and function of the nucleus and chromatin. Genes Dev. 22, 832-853.

Dechat, T., Adam, S., Goldman, R.D., 2009. Nuclear lamins and chromatin: when structure meets function. Adv. Enzyme Regul. 49, 157-166.

Diez, C., Duque, P., Gomez, E., Hidalgoa, C.O., Tamargo, C., Rodriguez, A., Fernandez, L., La Varga, S., Fernandez, A., Facal, N., Carbajo, M., 2005. Bovine oocyte vitrification before or after meiotic arrest: effects on ultrastructure and developmental ability. Theriogenology 64, 317-333.

Diez, C., Munõz, M., Caamanño, J.N., Gomez, E., 2012. Cryopreservation of the bovine oocyte: current status and perspectives. Reprod. Domest. Anim. 47, 76-83. 
Ezoe, K., Yabuuchi, A., Tani, T., Mori, C., Miki, T., Takayama, Y., Beyhan, Z., Kato, Y., Okuno, T., Kobayashi, T., Kato, K., 2015. Developmental competence of vitrified warmed bovine oocytes at the germinal vesicle stage is improved by cyclic adenosine monophosphate modulators during in vitro maturation. PLoS ONE 10, e0126801.

Ferreira, E.M., Vireque, A.A., Adona, P.R., Meirelles, F.V., Ferriani, R.A., Navarro, P.A. 2009. Cytoplasmic maturation of bovine oocytes: structural and biochemical modifications and acquisition of developmental competence. Theriogenology $71,836-$ 848.

Jiménez-Trigos, E., Naturil-Alfonso, C., Vicente, J., Marco-Jiménez, F., 2012. Effects of cryopreservation on the meiotic spindle, cortical granule distribution and development of rabbit oocytes. Reprod. Domest. Anim. 47, 472-478.

Kim, D., Park, H., Kim, S., Hwang, I., Yang, B., IM, G., Chung, H., Seong, H., Moon, S., Yang, B., 2007. Vitrification of immature bovine oocytes by the microdrop method. J. Reprod. Dev. 53, 843-851.

Ledda, S., Bogliolo, L., Succu, S., Ariu, F., Bebbere, D., Leoni, G.G., Naitana, S. 2007. Oocyte cryopreservation: oocyte assessment and strategies for improving survival. Reprod. Fertil. Dev. 19, 13-23.

Lee, K., Fodor, W.L., Machaty, Z., 2007. Dynamics of lamin A/C in porcine embryos produced by nuclear transfer. Mol. Reprod. Dev. 74, 1221-1227.

Morató, R., Izquierdo, D., Albarraci, J.L., Anguita, B., Palomo, M.J., Jiménez-Macedo, A.R., Paramio, M.T., 2008a. Effects of pre-treating in vitro-matured bovine oocytes with the cytoskeleton stabilizing agent taxol prior to vitrification. Mol. Reprod. Dev. 75, 191-201.

Morató, R., Izquierdo, D., Paramio, M.T., Mogas, T., 2008b. Cryotops versus Open-Pulled Straws (OPS) as carriers for the cryopreservation of bovine oocytes: effects on spindle 
and chromosome configuration and embryo development. Cryobiology. 57, 137-141.

Morató, R., Izquierdo, D., Paramio, M.T., Mogas, T., 2008c. Embryo development and structural analysis of in vitro matured bovine oocytes vitrified in flexipet denuding pipettes. Theriogenology 70, 1536-1543.

Morató, R., Mogas, T., Hyttel, P.M., 2008d. Ultrastructure of bovine oocytes exposed to taxol prior to OPS vitrification. Mol. Reprod. Dev. 75, 1318-1326.

Nohalez, A., Martinez, C.A., Gil, M.A., Almiñana, C., Roca, J., Martinez, E.A. \& Cuello, C., 2015. Effects of two combinations of cryoprotectants on the in vitro developmental capacity of vitrified immature porcine oocytes. Theriogenology $84,545-552$.

Prentice, J.R., Singh, J., Dochi, O., Anzar, M., 2011. Factors affecting nuclear maturation, cleavage and embryo development of vitrified bovine cumulus-oocyte complexes. Theriogenology 75, 602-609.

Prentice-Biensch, J.R., Singh, J., Mapletoft, R.J., Anzar, M., 2012. Vitrification of immature bovine cumulus-oocyte complexes: effects of cryoprotectants, the vitrification procedure and warming time on cleavage and embryo development. Reprod. Biol. Endocrinol. 73, 17.

Rho, G.J., Kim, S., Yoo, J.G., Balasubramanian, S., Lee, H.J., Choe, S.Y., 2002. Microtubulin configuration and mitochondrial distribution after ultra-rapid cooling of bovine oocytes. Mol. Reprod. Dev. 63, 464-470.

Rojas, C., Palomo, M.J., Albarracin, J.L., Mogas, T., 2004. Vitrification of immature and in vitro matured pig oocytes: study of distribution of chromosomes, microtubules, and actin microfilaments. Cryobiology 49, 211-220. 
Romek, M., Gajda, B., Rolka, M., Smorag, Z., 2011. Mitochondrial activity and morphology in developing porcine oocytes and pre-implantation non-cultured and cultured embryos. Reprod. Domest. Anim. 46, 471-480.

Ruchaud, S., Korfali, N., Villa, P., Kottke, T.J., Dingwall, C., Kaufmann, S.H. Earnshaw, W.C., 2002. Caspase-6 gene disruption reveals a requirement for lamin A cleavage in apoptotic chromatin condensation. EMBO J 21, 1967-1977.

Saunders, K.M., Parks, J.E., 1999. Effects of cryopreservation procedures on the cytology and fertilization rate of in vitro-matured bovine oocytes. Biol. Reprod. 61, 178-187.

Sripunya, N., Liang, Y., Panyawai, K., Srirattana, K., Ngernsoungnern, A., Ngernsoungnern, P., Ketudat-Cairns, M., Parnpai, R., 2014. Cytochalasin B efficiency in the cryopreservation of immature bovine oocytes by Cryotop and solid surface vitrification methods. Cryobiology 69, 496-499.

Sun, Q.Y., Wu, G.M., Lai, L., Park, K.W., Cabot, R., Cheong, H.T., Day, B.N., Prather, R.S., Schatten, H., 2001. Translocation of active mitochondria during pig oocyte maturation, fertilization and early development in vitro. Reproduction 122, 155-163.

Vajta, G., Holm, P., Kuwayama, M., Booth, P.J., Jacobsen, H., Greve, T., Callesen, H., 1998. Open Pulled Straw (OPS) vitrification : A new way to reduce cryoinjuries of bovine ova and embryos. Mol. Reprod. Dev. 58, 53-58.

Yan, C.L., Fu, X.W., Zhou, G.B., Zhao, X.M., Suo, L., Zhu, S.E., 2010. Mitochondrial behaviors in the vitrified mouse oocyte and its parthenogenetic embryo: effect of Taxol pretreatment and relationship to competence. Fertil. Steril. 93, 959-966.

Zhou, G.B., Li, N., 2013. Bovine oocytes cryoinjury and how to improve their development following cryopreservation. Anim. Biotechnol. 24, 94-106. 
Fig. 1. Representative confocal images of mitochondrial distribution (central - A and peripheral - B) in bovine oocytes after cryoprotectant exposure.

Fig. 2. Representative images of nuclear lamin and meiotic spindle organization. Regular (A) and irregular nuclear lamin (B), normal (C) and abnormal spindle (D). Nuclear lamin (A-B) and tubulin (C-D): red; chromosomes: blue; arrow: polar body.

Table 1 Distribution of groups in the experiments according to oocyte condition and treatment.

Experimental groups

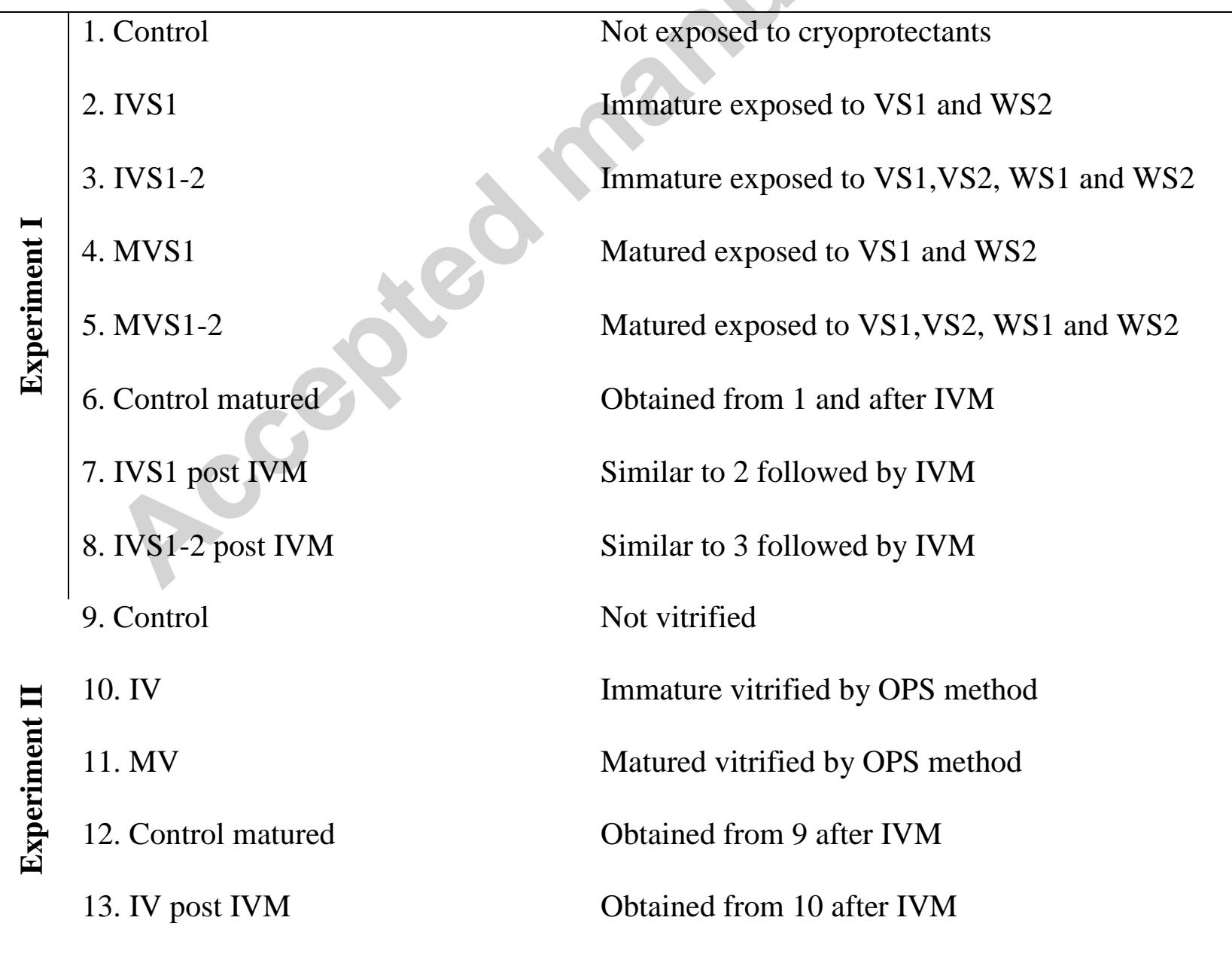


IVM: in vitro maturation, OPS: open pulled straw, VS: vitrification solution.

Table 2 Mitochondrial distribution in immature and in vitro matured bovine oocytes after cryoprotectant exposure.

\begin{tabular}{lcccc}
\hline \multicolumn{1}{c}{ Groups } & N & Viable rate (\%) & \multicolumn{2}{c}{ Distribution (\%) } \\
\cline { 3 - 5 } & & & Peripheral & Central \\
\hline Control & 19 & $19(100)^{\mathrm{a}}$ & $15(79)^{\mathrm{a}}$ & $4(21)^{\mathrm{a}}$ \\
IVS1 & 16 & $16(100)^{\mathrm{a}}$ & $9(56)^{\mathrm{ac}}$ & $7(44)^{\mathrm{ac}}$ \\
IVS1-2 & 18 & $15(83)^{\mathrm{ab}}$ & $12(80)^{\mathrm{a}}$ & $3(20)^{\mathrm{a}}$ \\
MVS1 & 18 & $18(100)^{\mathrm{a}}$ & $3(17)^{\mathrm{b}}$ & $15(83)^{\mathrm{b}}$ \\
MVS1-2 & 18 & $13(72)^{\mathrm{b}}$ & $3(23)^{\mathrm{bce}}$ & $10(77)^{\mathrm{bce}}$ \\
Control matured & 20 & $20(100)^{\mathrm{a}}$ & $8(40)^{\mathrm{bcd}}$ & $12(60)^{\mathrm{bcd}}$ \\
IVS1 post IVM & 19 & $19(100)^{\mathrm{a}}$ & $11(58)^{\mathrm{ade}}$ & $8(42)^{\mathrm{ade}}$ \\
IVS1-2 post IVM & 19 & $17(89)^{\mathrm{ab}}$ & $6(35)^{\mathrm{bce}}$ & $11(65)^{\mathrm{bce}}$ \\
\hline
\end{tabular}

Values with different letters in superscripts within same column are significantly different $(\mathrm{P}<$ $0.05)$. 
Table 3 Effect of cryoprotectant exposure on developmental competence of immature and in vitro matured bovine oocytes.

\begin{tabular}{lcccccc}
\hline Groups & $\mathrm{N}$ & Cleaved & Day 6 & Day 7 & Day 8 & Hatched/total \\
\cline { 4 - 6 } & & $(\%)$ & \multicolumn{3}{c}{ blastocysts (\%) } & blastocysts (\%) \\
\cline { 4 - 6 } & & & & & \\
Control & 199 & $177(89)^{\mathrm{a}}$ & $42(21)^{\mathrm{a}}$ & $94(47)^{\mathrm{a}}$ & $101(51)^{\mathrm{a}}$ & $43(22)^{\mathrm{a}}$ \\
IVS1 & 144 & $112(78)^{\mathrm{b}}$ & $34(24)^{\mathrm{a}}$ & $57(40)^{\mathrm{a}}$ & $59(41)^{\mathrm{a}}$ & $23(16)^{\mathrm{a}}$ \\
IVS1-2 & 108 & $70(75)^{\mathrm{c}}$ & $11(10)^{\mathrm{bc}}$ & $28(26)^{\mathrm{b}}$ & $31(29)^{\mathrm{b}}$ & $7(6)^{\mathrm{b}}$ \\
MVS1 & 144 & $104(72)^{\mathrm{bc}}$ & $21(15)^{\mathrm{abc}}$ & $30(21)^{\mathrm{b}}$ & $29(20)^{\mathrm{b}}$ & $10(7)^{\mathrm{b}}$ \\
MVS1-2 & 144 & $67(47)^{\mathrm{d}}$ & $10(7)^{\mathrm{c}}$ & $11(8)^{\mathrm{c}}$ & $12(8)^{\mathrm{c}}$ & $2(1)^{\mathrm{c}}$ \\
\hline Values with different letters in superscripts within same column are significantly different (P $<$ \\
0.05).
\end{tabular}

Table 4 Mitochondrial distribution in immature and in vitro matured bovine oocytes after vitrification.

\begin{tabular}{lcccc}
\hline Groups & N & Viable rate (\%) & \multicolumn{2}{c}{ Distribution (\%) } \\
\cline { 3 - 5 } & & & Peripheral & Central \\
\hline Control & 22 & $22(100)^{\mathrm{a}}$ & $15(68)^{\mathrm{a}}$ & $7(32)^{\mathrm{a}}$ \\
IV & 18 & $17(94)^{\mathrm{ac}}$ & $8(47)^{\mathrm{ab}}$ & $9(53)^{\mathrm{ab}}$ \\
Control matured & 23 & $23(100)^{\mathrm{a}}$ & $8(35)^{\mathrm{b}}$ & $15(65)^{\mathrm{b}}$ \\
MV & 18 & $13(72)^{\mathrm{bc}}$ & $6(46)^{\mathrm{ab}}$ & $7(54)^{\mathrm{ab}}$ \\
IV post IVM & 21 & $17(81)^{\mathrm{bc}}$ & $8(47)^{\mathrm{ab}}$ & $9(53)^{\mathrm{ab}}$
\end{tabular}

Values with different letters in superscripts within same column are significantly different $(\mathrm{P}<$ $0.05)$. 
Table 5 Effect of vitrification on developmental competence of immature and in vitro matured bovine oocytes.

\begin{tabular}{lcccccc}
\hline Groups & $\mathrm{N}$ & Cleaved & Day 6 & Day 7 & Day 8 & Hatched/total \\
\cline { 3 - 6 } & & $(\%)$ & & blastocyst $(\%)$ & & blastocysts (\%) \\
\hline Control & 256 & $203(79)^{\mathrm{a}}$ & $133(52)^{\mathrm{a}}$ & $101(39)^{\mathrm{a}}$ & $107(42)^{\mathrm{a}}$ & $47(18)^{\mathrm{a}}$ \\
IV & 156 & $13(8)^{\mathrm{c}}$ & $4(3)^{\mathrm{b}}$ & $0(0)^{\mathrm{b}}$ & $0(0)^{\mathrm{b}}$ & $0(0)^{\mathrm{b}}$ \\
MV & 113 & $22(19)^{\mathrm{b}}$ & $4(4)^{\mathrm{b}}$ & $1(1)^{\mathrm{b}}$ & $3(3)^{\mathrm{b}}$ & $1(1)^{\mathrm{b}}$ \\
\hline
\end{tabular}

Values with different letters in superscripts within same column are significantly different $(\mathrm{P}<$ $0.05)$.

Highlights

- Nuclear lamins in immature COC exhibited higher proportion of structures with irregular shape when treated with vitrification solutions.

- Immature oocytes exhibited more structures with irregular lamin (72\%) than control (9\%).

- The cleavage rate was higher in matured (19\%) than immature (8\%) vitrified group. 


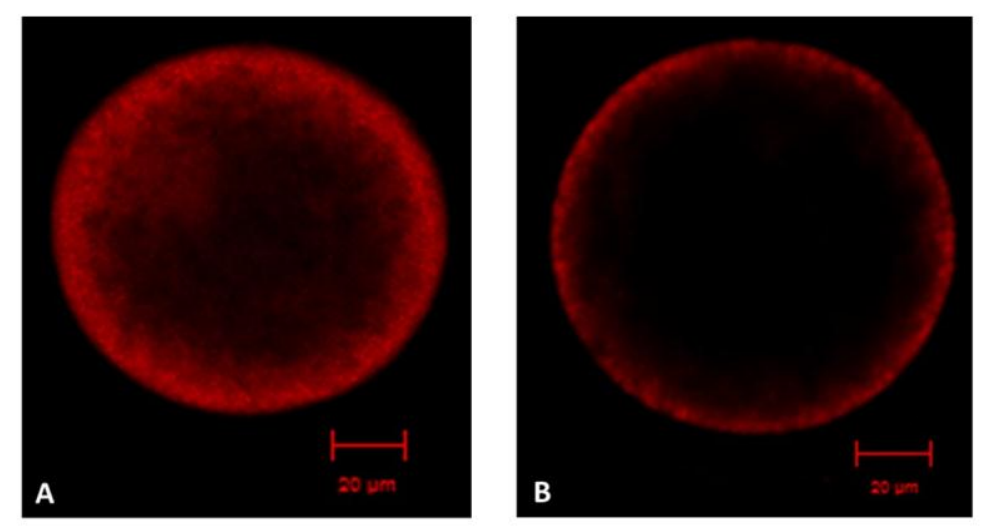




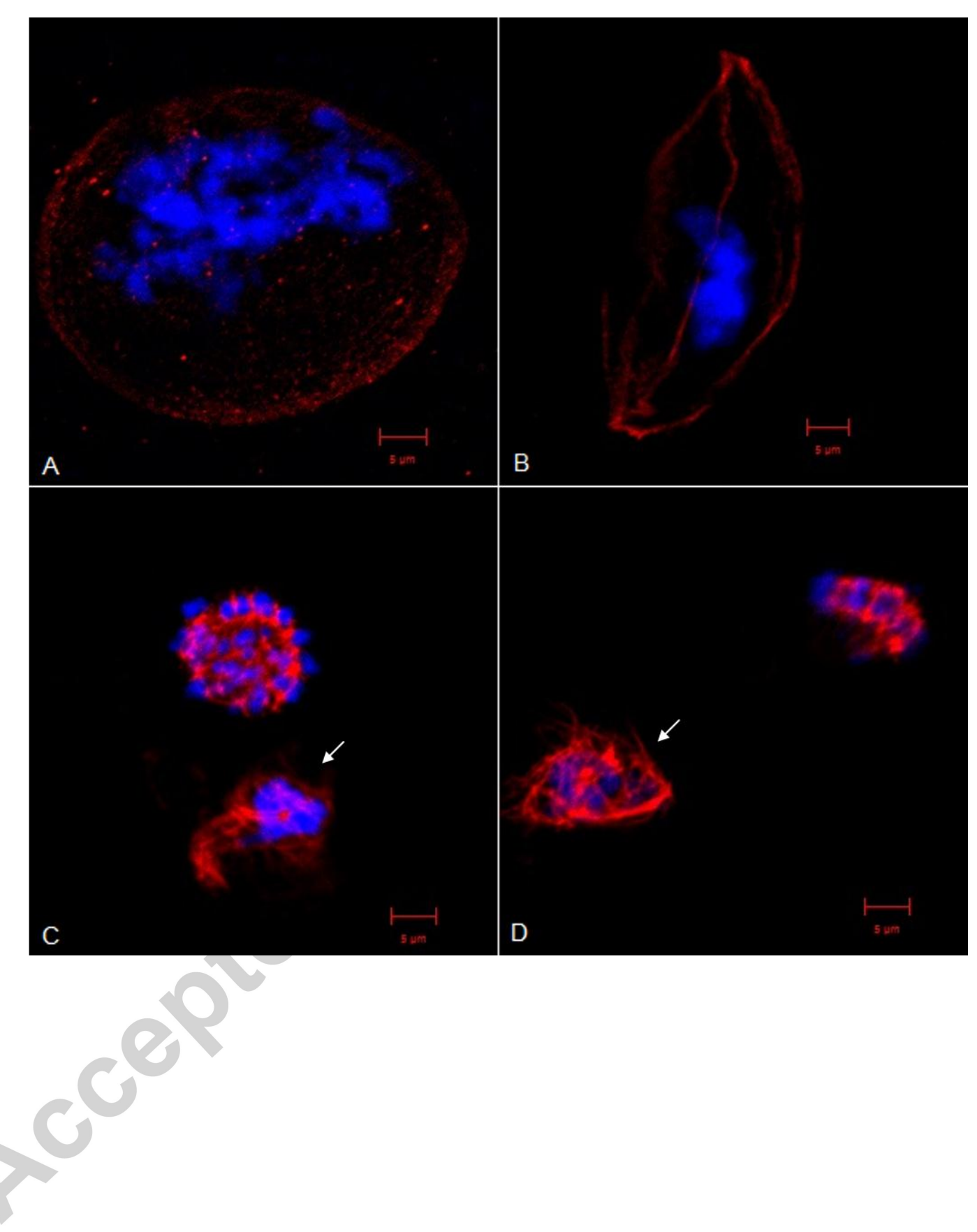

Comment citer ce document

Chaves, D. F., Corbin, E., Alminana, C., Locatelli, Y., Souza-Fabjan, J. M., Bhat, M. H.,

Freitas, V. J., Mermillod, P. (2017). Vitrification of immature and in vitro matured bovine cumulus-0ocyte complexes: effects on oocyte structure and embryo development. Livestock Science, 199, 50-56. DOl : 10.1016/i.livsci.2017.02.022 